\title{
Downstream Exposure to Growth Factors Causes Elevated Velocity and Dilation in Arteriolar Networks
}

\author{
Melissa K. Georgi Anthony M. Dewar Mary D. Frame \\ Department of Biomedical Engineering, Stony Brook University, Stony Brook, N.Y., USA
}

\section{Key Words}

Vascular endothelial cell growth factor A - Basic fibroblast

growth factor $\cdot$ Permeability $\cdot$ Extracellular matrix

\begin{abstract}
Our goal was to characterize changes in flow and diameter with vascular endothelial cell growth factor A (VEGF-A) and fibroblast growth factor 2 (FGF2). Observations were made in arteriolar networks of the cheek pouch tissue in anesthetized hamsters (pentobarbital $70 \mathrm{mg} / \mathrm{kg}$, i.p., $\mathrm{n}=45$ ). Local and remote dilation responses to micropipette-applied VEGF or FGF2 yielded similar $\mathrm{EC}_{50}$ values. The role of gap junctions in the remote response was tested by applying sucrose, halothane or $18 \alpha \mathrm{GA}$ to the feed arteriole midway between the remote stimulation and upstream observation sites; all remote dilation to FGF2 was prevented, while only the early dilation to VEGF was blocked. The remote dilation to VEGF displayed a second rheologic mechanism. The second mechanism involved an abrupt increase in upstream velocity and shear rate, followed by nitro-arginine sensitive dilation. To test whether the abrupt increase in shear could be caused by other agents known to cause edema, remote responses to histamine and thrombin were tested. Each caused an abrupt increase in velocity followed by nitro-argininesensitive dilation. This study shows that VEGF or agents that
\end{abstract}

increase permeability can initiate an upstream velocity increase with dilation that recruits flow to the network; this is in addition to simultaneous gap junction-mediated dilation.

Copyright ๑ 2010 S. Karger AG, Basel

\section{Introduction}

Growth factors have been extensively studied for their ability to cause cell proliferation, migration and angiogenesis over a time course of hours to weeks [1-3]. On a much shorter time scale, brief exposure of arterioles to some growth factors elevates capillary permeability and/ or alters arteriolar diameter within seconds [4-9]. The present study focuses on the vasoactive effects (of dilation and increased flow velocity) that occur during exposure to vascular endothelial cell growth factor A (VEGF-A 165) and basic fibroblast growth factor (bFGF, FGF2).

Local dilation to VEGF or FGF2 has been shown in isolated vessels (coronary, mesenteric arteries) or in whole animal preparations, where dilation has been linked to activation of growth factor receptor-specific tyrosine kinases, triggering either the MAPK cascade or (via Akt) nitric oxide (NO) production $[1,3,8,10-12]$. It has been unknown whether the growth factors could stimulate a remote microvascular response, for example, upstream

\section{KARGER}

(C) 2010 S. Karger AG, Basel

Fax +4161306 1234 E-Mail karger@karger.ch www.karger.com www.karger.com/jvr
Dr. Mary D. Frame

Department of Biomedical Engineering

Stony Brook University, Bioengineering G19

Stony Brook, NY 11794-5281 (USA)

Tel. +1 631632 1625, Fax +1 631632 3222, E-Mail mframe@ notes.cc.sunysb.edu 
changes in diameter during downstream exposure. Our preliminary data showed that VEGF-A and FGF2 each caused a remote vasodilation, which we hypothesized, would be mediated by gap junction signaling.

The physiological implication of growth factors causing a remote dilation would be that any small and localized exposure to growth factors could have an amplified effect on microvascular resistance and flow along the exposed flow path, well before angiogenic effects would be seen. In fact, the idea that growth factors contribute to angiogenesis via their vasoactive effects has been proposed $[13,14]$. Elevated flow alone is itself angiogenic and can induce release of growth factors [14, 15]; elevated flow caused by growth factors could provide a pro-angiogenic signal that would be in addition to their proliferative effects. Localized growth factor exposure explicitly causing changes in arteriolar flow has not been reported. We have previously characterized the flow recruitment response that occurs with remote ligation of the $\alpha_{v} \beta_{3}$ integrin, the vitronectin receptor, [16-19], a receptor which classically binds to the RGD sequence of extracellular matrix proteins, such as vitronectin and fibronectin, and is tightly linked to angiogenesis [20]. We have shown that microvascular flow is recruited exclusively to the flow path that is stimulated via $\alpha_{v} \beta_{3}$ receptor ligation, to the extent that flow is stolen from parallel flow paths [16]. We hypothesized that a component of the total rheologic response with VEGF and FGF2 would likewise include a rapid elevation in flow velocity as a universal signal accompanying angiogenic agents.

Lastly, it was important to choose concentrations of these growth factors that are physiologically relevant. In brief, the range of concentrations of VEGF and FGF2 that were tested here covers the range reported for interstitial concentrations of these growth factors, and those typically reported to cause other physiological effects (see Discussion). Importantly, the total growth factor pool includes those encrypted within extracellular matrix proteins, but also bound to specific cellular receptors [21,22]. Further, the estimated basal VEGF, as an example, that is bound to endothelial cells is likely 3 -fold less than total binding capacity [23], indicating a large capacity in response to a sudden increase in VEGF. Thus, the rheologic responses we report are consistent with acute localized exposure to growth factor that could be released from a pool associated with or encrypted within the extracellular matrix, such as with mechanically induced conformational changes of the matrix.

\section{Methods}

\section{Animal Model}

All animal procedures were done with the approval of Stony Brook University Institutional Animal Care and Use Committee. Adult male hamsters ( $81 \pm 19$ days; $106 \pm 16 \mathrm{~g} ; \mathrm{n}=45)$ were anesthetized (pentobarbital sodium $70 \mathrm{mg} / \mathrm{kg}$, i.p.), tracheostomized, and for 26 of these hamsters, an indwelling jugular catheter was placed, for administration of fluorescently labeled red blood cells (flow markers). The left cheek pouch was prepared for intravital microscopy observations, and was superfused with a control physiological saline solution $\left(0 \% \mathrm{O}_{2}, 5 \% \mathrm{CO}_{2}\right.$; pH 7.4, $\mathrm{HCO}_{3}$ buffer). Dilatory tone was confirmed with topical adenosine $\left(10^{-4} \mathrm{M}\right)$. Red blood cells were obtained from age- and weight-matched donor hamsters (78 \pm 26 days; $106 \pm 13 \mathrm{~g}$; $\mathrm{n}=17)$; the cells were labeled with rhodamine isothiocyanate (XRITC) using an established protocol [24]. The XRITC cells were administered 30-45 min prior to data collection, to ensure uniform mixing within the circulatory system.

Arteriolar Network, Exposure Locations and Concentrations

Our laboratory deliberately chooses arteriolar networks to study vasoactive responses (fig. 1). The arteriolar network is a repeating structure across the hamster cheek pouch tissue; they arise from (nonnutritive) arcading arterioles, and consist of a central feed arteriole and 3-7 terminal branch arterioles [16, 25-27]. The terminal branch arterioles perfuse only capillaries [28]; thus, flow into these networks is solely nutritional. Similar arteriolar structures are seen in the cremaster muscle of the hamster, rat or mouse $[10,29]$.

All exposures to test agents were via micropipette application, using a minimal ejection pressure (typically $0.2-0.3$ psi; PIL-100 Medical Systems, Greenvale, N.Y., USA), with a balance pressure set so that fluids were not ejected in the holding configuration. All micropipettes were backfilled with test agents, containing 10 $\mu \mathrm{M}$ fluorescein isothiocyanate (FITC) conjugated to 4,000 MW dextran. The micropipette was placed above the arteriole and within $25 \mu \mathrm{m}$ of the selected arteriolar segment. During exposure, the FITC was observed to flow out of the micropipette, over the selected arteriolar segment, and to wash away from the other locations of the network (that is, not recirculated from the remote to the local observation site, or vice versa). The micropipette tip size was $20-40 \mu \mathrm{m}$ in diameter and the FITC flow stream was observed to be roughly double that in diameter $(40-100 \mu \mathrm{m})$ at the point the pipette contents washed over the exposure site, as before [30].

A relevant question is: what is the concentration of the test agents at the vessel wall? Using a simple calculation where the pipette contents are diluted from the pipette to the FITC flow stream, so that the effective radius doubles from the pipette (10 $\mu \mathrm{m})$ to the FITC flow stream $(20 \mu \mathrm{m})$, the cross-sectional area exiting the pipette containing the FITC would increase by a factor of 4 , and therefore the concentration within the flow stream would be diluted to $25 \%$ of that in the pipette. Alternately, using an estimate of simple diffusion $\left(\mathrm{D}=10^{-6} \mathrm{~cm}^{2} / \mathrm{s}\right)$ of the test agent from the FITC flow stream to the arteriolar wall (approx. $25 \mu \mathrm{m}$ ), the concentration at the wall would be $50 \%$ of that in the pipette by the end of a 60 -second exposure. This effective concentration range at the wall has implications for our interpretation of the data (see Discussion). 
Following a 30-second baseline, local or remote test responses were obtained. In all cases, at individual networks, 4-5 concentrations were applied sequentially, in increasing order, using a 60 -second exposure, followed by 5-10 min recovery after each exposure. Recovery was defined as a return to baseline diameter. Only 1 test agent was tested per arteriolar network, with between 2 and 4 networks tested per animal.

\section{Protocol 1: Local Responses}

Local responses were obtained by micropipette application of a test drug to the abluminal surface of the upstream entrance to the arteriolar network, labeled A in figure 1, while observing microvascular changes at location A. Local responses were obtained in response to VEGF $(0.1-1,000 \mathrm{ng} / \mathrm{ml}$ in the pipette) or to FGF2 $(0.1-1,000 \mathrm{ng} / \mathrm{nl}$ in the pipette).

\section{Protocol 2: Remote Responses}

Remote responses were obtained by micropipette application of the test drug to one of the two downstream-most terminal branch arterioles of the network, labeled $\mathrm{C}$ in figure 1, while observing microvascular changes upstream at location A. Remote responses were obtained in response to VEGF $(0.1-1,000 \mathrm{ng} / \mathrm{ml}$ in the pipette), FGF2 (0.1-1,000 $\mathrm{ng} / \mathrm{ml}$ in the pipette), histamine (50 $\mu \mathrm{M})$ and thrombin $(5 \mathrm{U} / \mathrm{ml})$.

\section{Protocol 3: Testing Involvement of Gap Junctions}

Control remote responses were obtained in response to 100 $\mathrm{ng} / \mathrm{ml}$ VEGF or FGF2 in the pipette. Gap junctions were nonspecifically blocked by using halothane (3.4 mM), high-osmolar sucrose (150 mOsm sucrose in $150 \mathrm{mOsm}$ control suffusate) or 50 $\mu \mathrm{M} 18 \alpha \mathrm{GA}$, applied to location B (fig. 1), for $5 \mathrm{~min}$ prior to and during the second exposure to the growth factor at location $\mathrm{C}$. This tested whether the downstream application of growth factor caused a remote dilation that was transmitted by gap junctional communication along the central feed arteriole of the network.

\section{Protocol 4: Testing Involvement of Upstream Flow-Mediated}

Dilation

Control remote responses were obtained in response to 100 $\mathrm{ng} / \mathrm{ml}$ VEGF or FGF2, histamine $50 \mu \mathrm{M}$, or thrombin $5 \mathrm{U} / \mathrm{ml}$. $\mathrm{N \omega}$ nitro-L-arginine (LNNA; $50 \mu \mathrm{M}$ ) was applied via micropipette to location A upstream, for $5 \mathrm{~min}$ prior to and during the second exposure to the test agent at location $\mathrm{C}$. This tested whether the increase in upstream shear rate caused an upstream dilation that was NO mediated (for example flow-mediated dilation).

\section{Data Acquisition and Analysis}

Arteriolar diameter of location A was continuously monitored and recorded (SVHS, Panasonic AG7350) for $30 \mathrm{~s}$ prior to test conditions and during test exposures. In 26 animals, both arteriolar diameter and XRITC cell velocity were obtained simultaneously, using brightfield and epi-illumination with a modified upright Nikon microscope, and visualized with an intensified camera system (XR/mega 10; Solamere Technology Group Inc., Salt Lake City, Utah, USA). Optical magnification was $50 \times$ (Nikon, N.A. 0.45 ) or $60 \times$ SWI (Nikon, N.A. 0.90), providing an optical resolution of 0.71 or $0.35 \mu \mathrm{m}$, respectively, for white light. The final magnification for online measurements was $900 \times$ or $1,000 \times$, and final magnification for offline measurements pro-

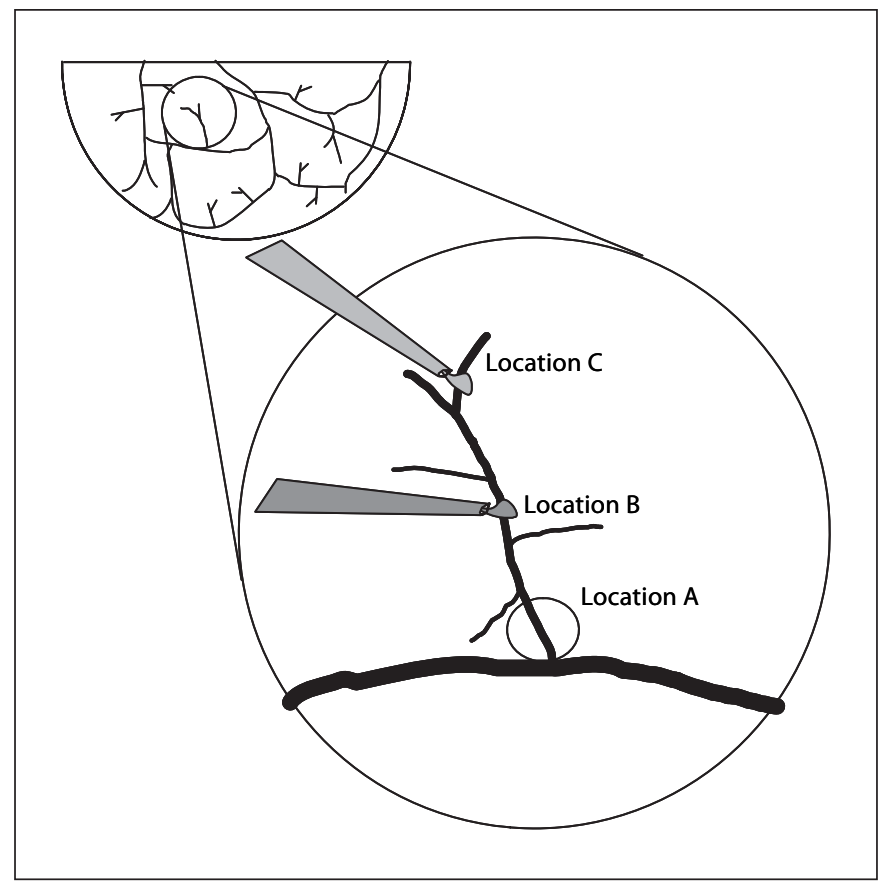

Fig. 1. Shown is a schematic of the arteriolar circulation in the hamster cheek pouch, with an expanded view of the arteriolar network. Multiple arteriolar networks arise from the extensive arcading system. All observations of diameter and blood flow were made at location A. All test agents were applied via micropipette. Test agents were applied to location A, the entrance to the network to obtain local responses (protocol 1, Methods). Test agents were applied to location $\mathrm{C}$ to obtain remote responses (protocol 2). To test the involvement of gap junctional communication in these responses, the gap junction inhibitors were applied to location B (protocol 3). To test the involvement of flow-mediated dilation at location A, LNNA (nitro-arginine) was applied to location A (protocol 4).

vided a pixel dimension of $0.3 \times 0.3 \mu \mathrm{m}$. Diameter was measured online (Strawberry Tree Inc., Sunnyvale, Calif., USA). XRITC cell velocity was obtained offline by converting the NTSC signals to avi digital images, preserving $1 / 60$ th second temporal resolution (XCap; Xcitex, Cambridge, Mass., USA). Velocities of individual XRITC cells were obtained using a videostreaming particle tracking program (ProAnalyst; MiDAS). Cell flux was obtained by manually counting the numbers of XRITC-labeled cells within the prescribed time window. The number of total cells represented by the XRITC-labeled fraction was determined by analysis of a blood sample obtained at the end of the experiment.

\section{Statistical Analysis}

The diameter response was calculated as the peak change in diameter $(\mu \mathrm{m})$ minus the baseline diameter, divided by baseline diameter. In select experiments, the diameter change is reported for each 5-second interval. In most cases, diameter change is re- 


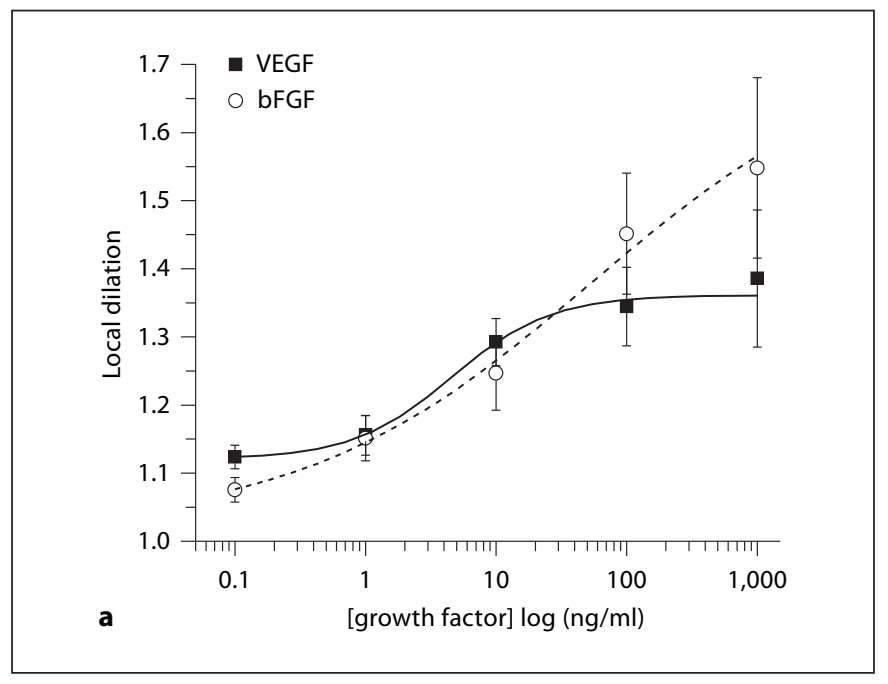

Fig. 2. Shown is the normalized change in diameter $[1+$ (peak baseline)/baseline] for the local (a) and remote (b) responses to growth factors. The $\mathrm{x}$-axis shows the concentration in the micropipette. a Local response relationships for VEGF $(n=9)$ and for

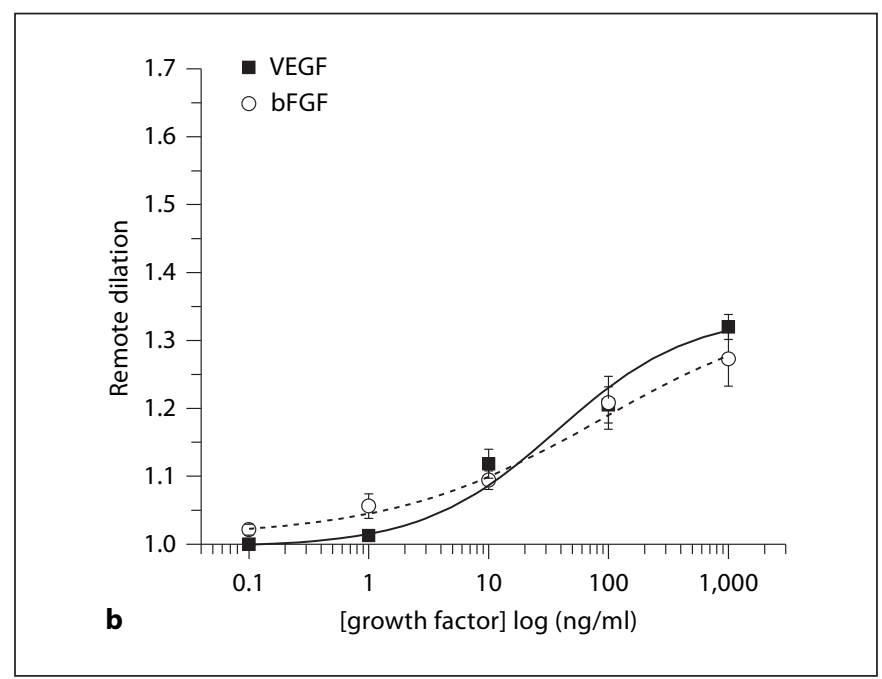

FGF2 ( $\mathrm{n}=7$ ), using protocol 1 . b Remote dilation response relationships for VEGF $(n=9)$ and FGF2 $(n=10)$, using protocol 2. The fitted $\mathrm{EC}_{50}$ and maximal values are in table 2. Data are presented as means \pm SEM.
Table 1. Length of network, baseline and maximal diameter, red blood cell velocity and flux

\begin{tabular}{lcc}
\hline Parameter & Baseline control value $^{\mathrm{a}}$ \\
\hline Network feed length, $\mu \mathrm{m}$ & $735 \pm 306$ & $(83$ networks in 45 animals $)$ \\
Baseline diameter $^{\mathrm{b}}, \mu \mathrm{m}$ & $7.3 \pm 2.6$ & $(83$ networks in 45 animals $)$ \\
Maximal diameter $^{\mathrm{a}, \mathrm{c}}, \mu \mathrm{m}$ & $12.9 \pm 3.3$ & $(83$ networks in 45 animals $)$ \\
Velocity $^{\mathrm{b}}, \mu \mathrm{m} \cdot \mathrm{s}^{-1}$ & $785 \pm 462$ & $(42$ networks in 17 animals $)$ \\
Shear rate $^{\mathrm{b}}, \mathrm{s}^{-1}$ & $1,107 \pm 1,004$ & $(42$ networks in 17 animals $)$ \\
RBC flux $^{\mathrm{b}}, \mathrm{n} \cdot \mathrm{s}^{-1}$ & $761 \pm 735$ & $(42$ networks in 17 animals $)$ \\
\hline
\end{tabular}

$\mathrm{RBC}=$ Red blood cell. ${ }^{\mathrm{a}}$ Entries are the mean $\pm \mathrm{SD}$ for each population. ${ }^{\mathrm{b}}$ Values at location A. ${ }^{\mathrm{c}}$ Topical adenosine, $10^{-4} \mathrm{M}$. ported for the peak change occurring by $15 \mathrm{~s}$ of exposure (early) and the peak change occurring by $60 \mathrm{~s}$ of exposure (late). These time values were chosen based on analysis of the total response over $60 \mathrm{~s}$ of exposure. Shear rate $\left(\mathrm{s}^{-1}\right)$ was calculated assuming a parabolic velocity profile, as 8 times the harmonic mean velocity $(\mu \mathrm{m} / \mathrm{s})$ [31], divided by the diameter. As with diameter changes, in select experiments, velocity or shear rate is shown for each 5 -second interval, but most values are reported for the early and late responses. Cell flux is given as the number of total red blood cells passing through the arteriolar segment per second. Concentration response relationships were analyzed for the $\mathrm{EC}_{50}$ and maximal values, and statistical comparisons were made using ANOVA for repeated measures. Where individual responses to single doses were obtained before and after inhibitor treatments, comparisons were made by paired t test. All statistical comparisons were considered using $\mathrm{p}<0.05$ [32].

\section{Results}

Baseline values for diameter, harmonic mean velocity, shear rate and red blood cell flux, with total network lengths, are shown in table 1 . These values did not vary by experimental groups.

Figure 2 shows the local response relationships for VEGF and for FGF2 using protocol 1, and the remote response relationships for these growth factors using protocol 2. The $\mathrm{EC}_{50}$ and maximal dilation values are in table 2. Note that the local response to FGF2 did not reach a plateau by $1,000 \mathrm{ng} / \mathrm{ml}$, and thus the fit is approximate. Neither the $\mathrm{EC}_{50}$ nor the maximal dilation was significantly different for local or the remote dilation to these 


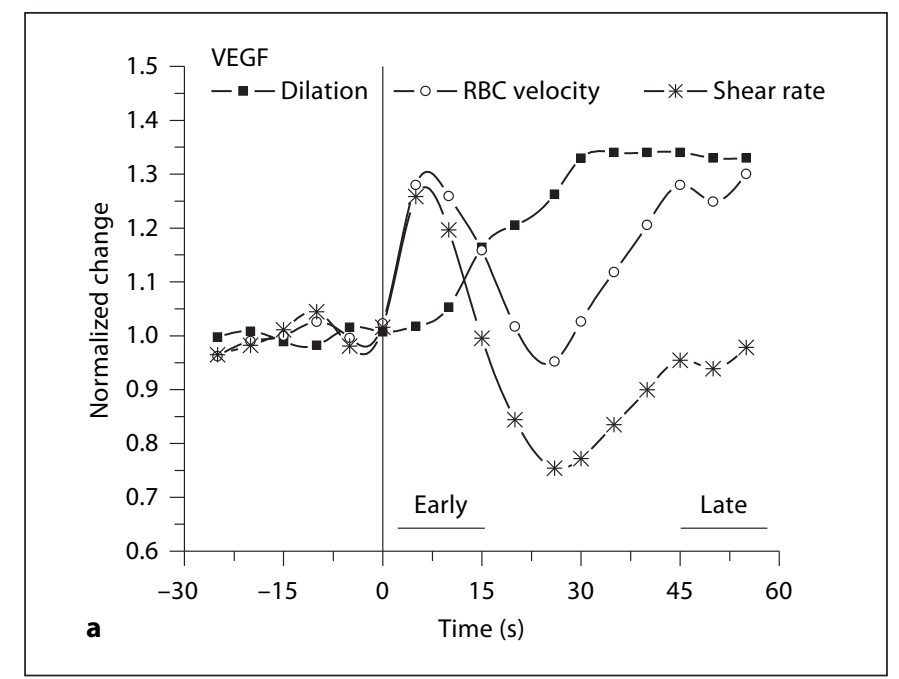

Fig. 3. Shown are the normalized remote velocity, diameter and shear rate values $[1+$ (peak - baseline)/baseline $]$ as a function of time with downstream VEGF $(\mathbf{a}, \mathrm{n}=11)$ or FGF2 $(\mathbf{b}, \mathrm{n}=7)$ at 1,000 $\mathrm{ng} / \mathrm{ml}$ in the micropipette. Data was binned for each $5 \mathrm{~s}$; error bars

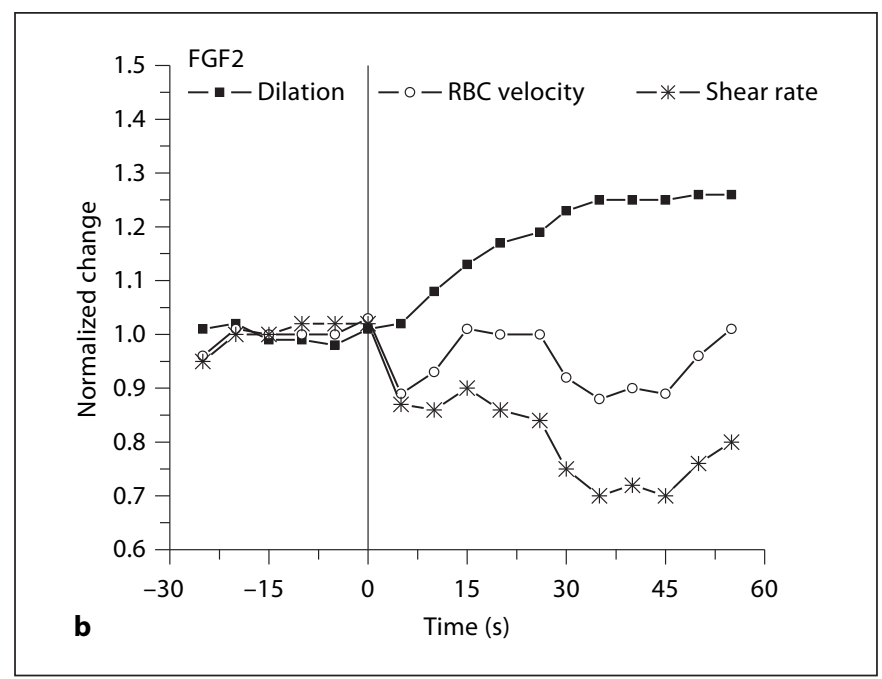

intentionally left off to observe trends. A 30 -second baseline preceded a 60-second remote exposure; exposure onset is at $0 \mathrm{~s}$ on this graph.
Table 2. Fitted ${ }^{\mathrm{a}} \mathrm{EC}_{50}$ and maximal values for VEGF and FGF2 exposure

\begin{tabular}{|c|c|c|c|c|}
\hline & & $\begin{array}{l}\mathrm{EC}_{50} \\
\mathrm{ng} / \mathrm{ml}\end{array}$ & $\begin{array}{l}\text { Maximal } \\
\text { response }^{b}\end{array}$ & $\begin{array}{l}\text { Graph contain- } \\
\text { ing data }\end{array}$ \\
\hline \multirow[t]{6}{*}{ VEGF } & Local exposure & & & \\
\hline & Dilation & $5 \pm 0.4$ & $1.36 \pm 0.001$ & figure 2 \\
\hline & Remote exposure & & & \\
\hline & Dilation & $33 \pm 15$ & $1.43 \pm 0.71$ & figure 2 \\
\hline & Shear rate & $54 \pm 22$ & $1.30 \pm 0.11$ & figure 4 \\
\hline & RBC flux & $3.9 \pm 1.1$ & $2.30 \pm 0.05$ & figure 5 \\
\hline \multirow[t]{6}{*}{ FGF2 } & Local exposure & & & \\
\hline & Dilation & $53 \pm 43$ & $1.73 \pm 0.12$ & figure 2 \\
\hline & Remote exposure & & & \\
\hline & Dilation & $42 \pm 8$ & $1.29 \pm 0.06$ & figure 2 \\
\hline & Shear rate ${ }^{c}$ & $\mathrm{n} / \mathrm{a}$ & $\mathrm{n} / \mathrm{a}$ & figure 4 \\
\hline & RBC flux & $32 \pm 21$ & $2.20 \pm 0.21$ & figure 5 \\
\hline
\end{tabular}

Entries are mean \pm SEM with corresponding $\mathrm{n}$ in the figure legends. ${ }^{\text {a }}$ Values are fitted using the concentration within the micropipette. ${ }^{b}$ Maximal values are normalized changes over baseline. ${ }^{c}$ Shear rate did not change with FGF2. growth factors. Thus, in terms of ability to dilate, these growth factors induce a similar change in vascular resistance locally and remotely along the central feed arteriole of the terminal arteriolar network.

Clear differences in the mechanisms of these responses to VEGF and FGF2 became apparent when examining the changes in red blood cell velocity over time. With remote exposure to VEGF (protocol 2), there was a sudden increase in velocity that preceded remote dilation. This effect is illustrated over time showing response with $1,000 \mathrm{ng} / \mathrm{ml}$ VEGF or FGF2 (fig. 3). It was clear that the shear rate peaked within the first $15 \mathrm{~s}$ of VEGF exposure, and then returned to baseline by $45-60 \mathrm{~s}$ of exposure. This trend was also apparent with $100 \mathrm{ng} / \mathrm{ml}$ VEGF (data not shown). In contrast, with FGF2, upstream changes in velocity and shear appear to be passive and due to dilation 


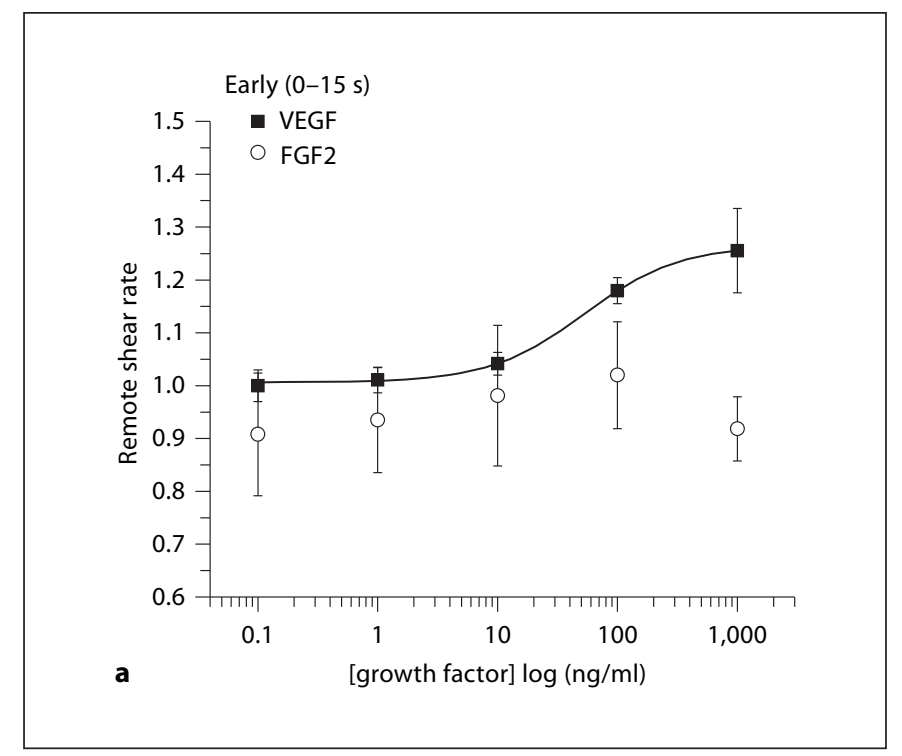

Fig. 4. Shown is the normalized remote shear rate $[1+$ (peak baseline)/baseline] upstream with downstream application of growth factors, using protocol 2 . The $\mathrm{x}$-axis shows the concentration in the micropipette. Early (a) and late (b) responses for VEGF

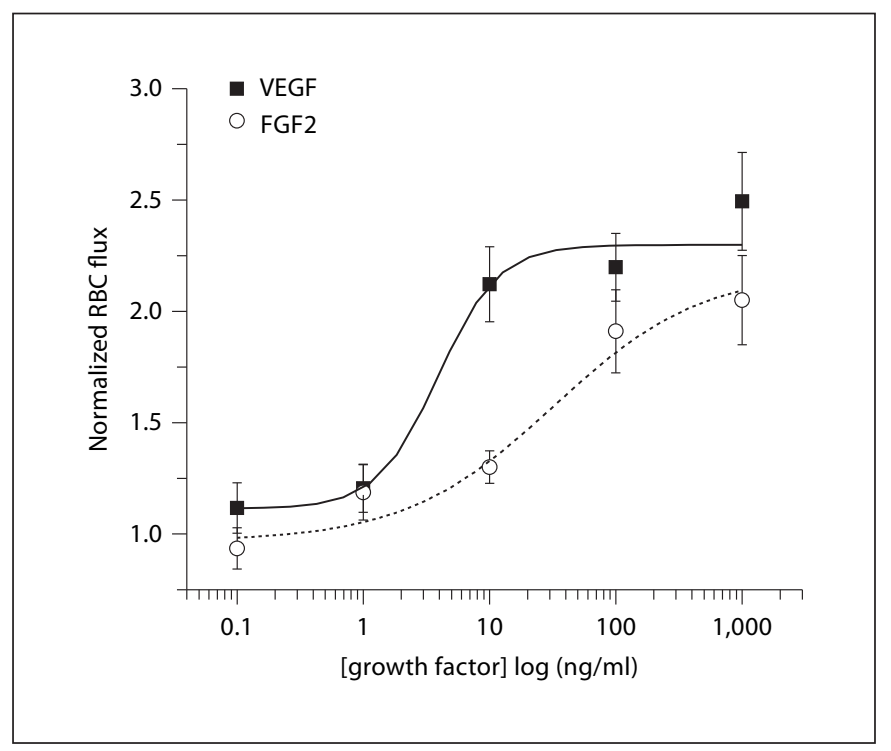

Fig. 5. Shown is the normalized change in red blood cell flux $[1+$ (peak - baseline)/baseline] into the network with downstream application of VEGF $(n=6)$ or FGF2 $(n=6)$, using protocol 2. The $\mathrm{x}$-axis shows the concentration in the micropipette. Data are presented as means \pm SEM.

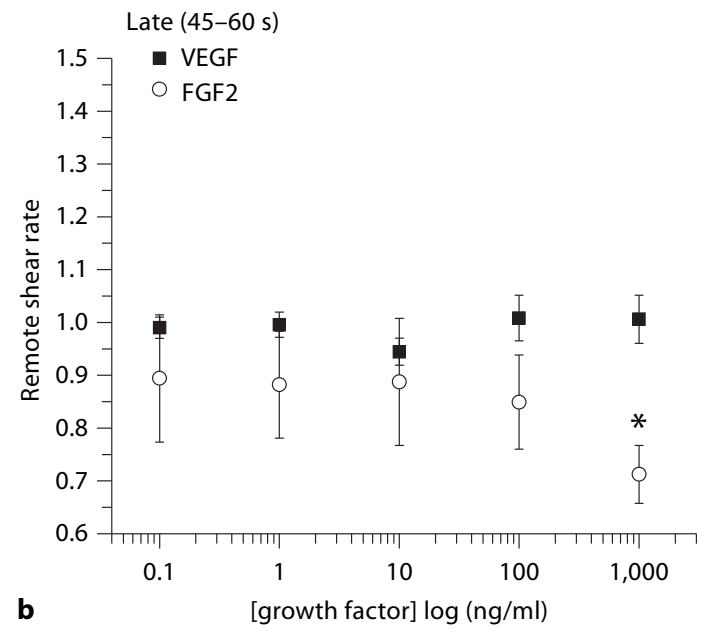

$(\mathrm{n}=6)$ and for FGF2 $(\mathrm{n}=6)$, as defined in figure $3 \mathrm{a}$. The $\mathrm{EC}_{50}$ and maximal values are in table $2 .{ }^{*}$ Significantly less than baseline. a $1,000 \mathrm{ng} / \mathrm{ml} \mathrm{FGF} 2$ does not differ from baseline $(\mathrm{p}=0.09)$. Data are presented as means \pm SEM.

alone. We therefore examined the early change in shear rate (between 0 and $15 \mathrm{~s}$ of exposure) and compared this to the late change in shear rate (between 45 and $60 \mathrm{~s}$ of exposure) in subsequent experiments. Figure 4 shows the early and late calculated shear rate values during VEGF or FGF2, as a function of concentration. Early changes in shear rate with VEGF were significant with 100 or 1,000 $\mathrm{ng} / \mathrm{ml}$ (significance not marked on graph), while changes with FGF2 were more variable and not significantly different from baseline values. Late changes with either growth factor were variable, and were not different from baseline, excepting a significant decrease in late shear rate with FGF2 at $1,000 \mathrm{ng} / \mathrm{ml}$. The combined dilation and increased velocity resulted in a significant increase in red blood cell influx to the arteriolar network for VEGF, while increased flux was due to only diameter changes for FGF2 (fig. 5).

To test whether the remote dilation to growth factors was transmitted by gap junctions, (separately) 3 gap junction inhibitors were applied midway between the observation and growth factor exposure sites (location B; fig. 1). Figure 6 shows that the early dilation (by $15 \mathrm{~s}$ of exposure) was attenuated by gap junction inhibition for VEGF or FGF2. The late dilation (45-60 s) was not significantly prevented by these inhibitors for VEGF, yet was prevented for FGF2. Thus, the remote dilation to FGF2 


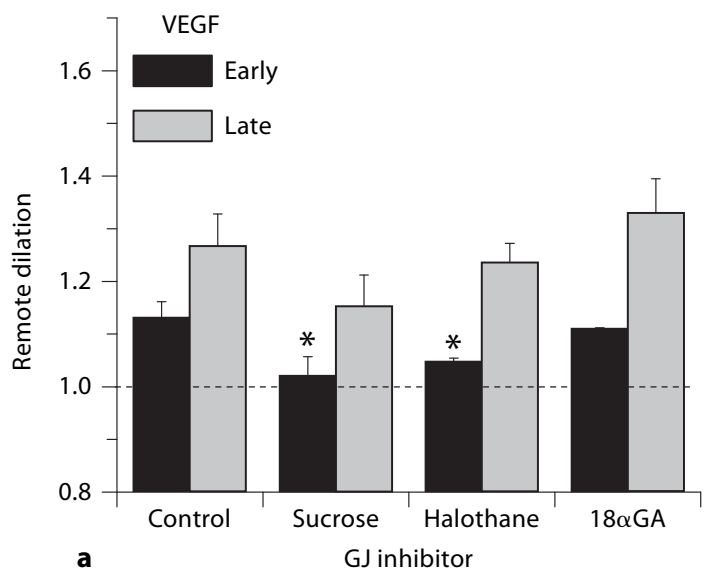

Fig. 6. Shown is the normalized change in diameter $[1+$ (peak baseline)/baseline] for the remote dilation to growth factors with and without gap junction inhibition, using protocol 3. Early and late dilation responses are noted for $100 \mathrm{ng} / \mathrm{ml} \operatorname{VEGF}(\mathbf{a}, \mathrm{n}=7)$ or

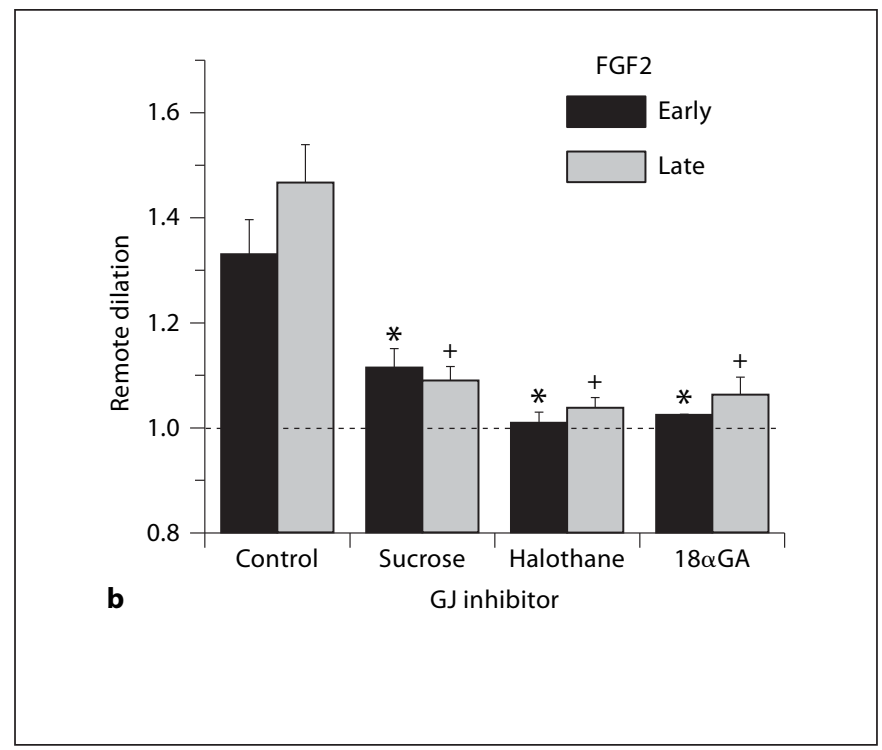

FGF2 (b, $\mathrm{n}=6)$ during control, or simultaneously with a gap junction inhibitor: sucrose, $150 \mathrm{mOsm}$ sucrose plus control suffusate; halothane, $3.4 \mathrm{mM}$; $18 \alpha \mathrm{GA}, 50 \mu \mathrm{M} .{ }^{*}$ Differs from early control; ${ }^{+}$differs from late control. Data are presented as means \pm SEM.
Fig. 7. Shown is the normalized change in diameter $[1+$ (peak - baseline)/baseline $]$ for the remote dilation response to growth factors with and without LNNA, using protocol 4. Early and late dilation responses are noted for $100 \mathrm{ng} / \mathrm{ml} \operatorname{VEGF}(\mathbf{a}, \mathrm{n}=6)$ or FGF2 (b, $\mathrm{n}=5)$ during control, or simultaneously with LNNA $(50 \mu \mathrm{M})$. * Differs from early. Data are presented as means \pm SEM.


appears to be entirely a gap junction-mediated response. In contrast, only the initial component of the dilation to VEGF appears to be gap junction mediated, and this component is not significantly blocked by $18 \alpha \mathrm{GA}$. In contrast, the secondary component of the remote dilation to VEGF is not gap junction mediated.

Due to the abrupt increase in upstream shear rate that immediately accompanied downstream VEGF exposure, we hypothesized that the secondary component of the VEGF remote dilation was a flow-mediated dilation. Figure 7 shows that LNNA had no effect on the FGF2 remote response, as expected. With VEGF, LNNA did not pre- vent the abrupt increase in shear rate upstream, nor the initial component to the remote dilation. Only the secondary remote dilatory component was prevented by LNNA. Thus, the secondary component of the remote dilation to VEGF appears to be a flow-mediated dilation in response to the abrupt increase in upstream shear rate.

The cause of the abrupt increase in upstream shear rate could be due to sudden fluid extravasation (increased permeability) downstream, caused by VEGF exposure (see Discussion). We hypothesized, therefore, that any agent causing an abrupt increase in permeability would likewise trigger an upstream increase in shear rate and 


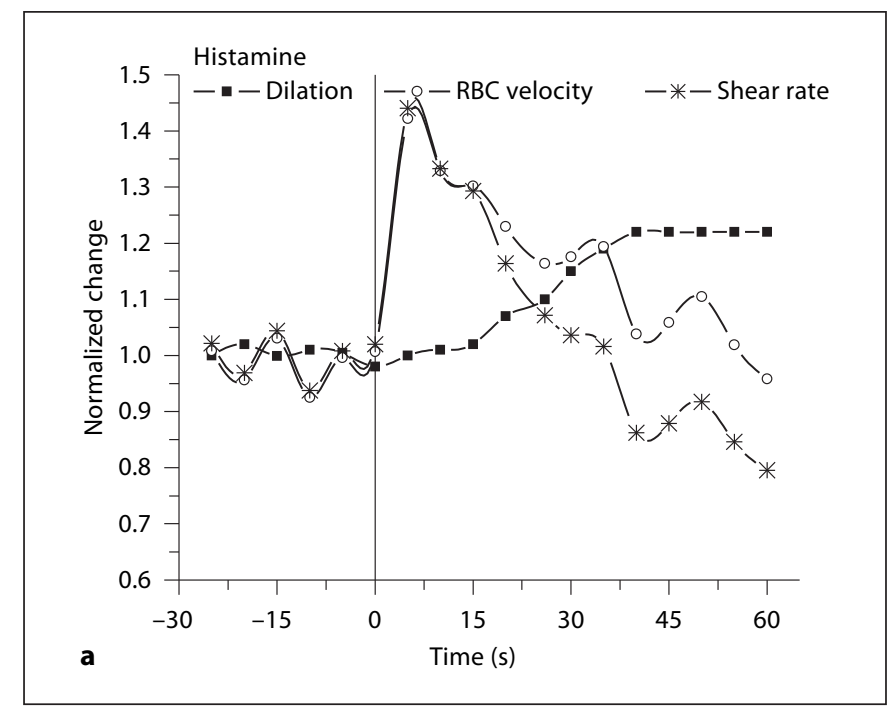

Fig. 8. Shown are the normalized velocity, diameter and shear rate values $[1+$ (peak - baseline)/baseline] as a function of time with histamine $(\mathbf{a}, 50 \mu \mathrm{M}, \mathrm{n}=10)$ and thrombin $(\mathbf{b}, 5 \mathrm{U} / \mathrm{ml}, \mathrm{n}=10)$. Data was binned for each $5 \mathrm{~s}$; error bars intentionally left off to

subsequent dilation. Figure 8 shows the remote response with histamine and thrombin, each well documented to increase local permeability [33,34]. Figure 8 shows that each agent caused an abrupt increase in upstream velocity and shear rate, which was followed by a remote vasodilation. Comparing the time course of these dilations to those caused by VEGF or FGF2 (fig. 4; 5-10 s), dilation onset is as much as $20-25 \mathrm{~s}$ after the onset of histamine or thrombin application. Thus, these agents, known to increase permeability, also caused a remote rheological response that consisted of an abrupt increase in velocity followed by a remote vasodilation. The accompanying increase in red blood cell flux was $1.75 \pm 0.18$ fold over baseline with histamine, and $1.90 \pm 0.2$ fold over baseline with thrombin $(\mathrm{n}=10$ each). Lastly, we tested whether the dilation component to histamine and thrombin could be blocked by LNNA (protocol 4). The control remote dilation to histamine $(50 \mu \mathrm{M}, 1.32 \pm 0.06, \mathrm{n}=3)$ was prevented by LNNA $(50 \mu \mathrm{M}, 1.03 \pm 0.05)$ and likewise with thrombin $(1.29 \pm 0.05$ vs. $1.09 \pm 0.07, \mathrm{n}=3)$. This suggests that the remote dilation component to these permeability-increasing agents is flow mediated, and in response to the abrupt increase in upstream velocity.

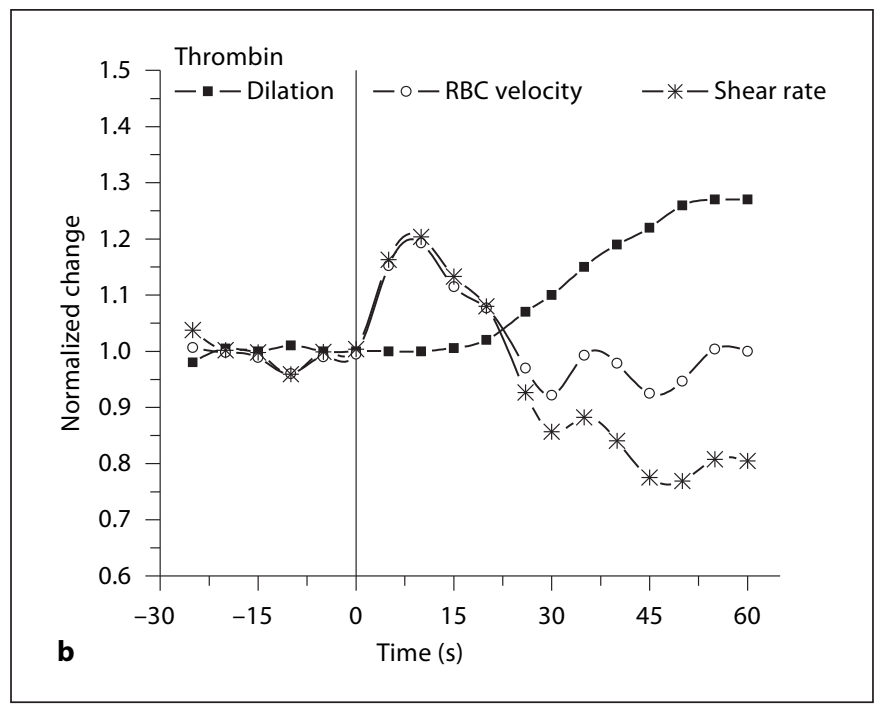

observe trends. The values are normalized to the average baseline. A 30 -second baseline preceded a 60-second remote exposure (at $30 \mathrm{~s}$ on this graph).

\section{Discussion}

This study provides several novel findings. First, VEGF-A and FGF2 each stimulate a remote vasodilation that recruits flow at physiologically relevant concentrations. Second, while FGF2 appears to be causing a remote dilation via only gap junction signaling, the remote dilation with VEGF consists of at least two separate rheologic mechanisms: the early dilation is gap junction dependent and the secondary later dilation is flow mediated caused by an abrupt elevation in upstream shear rate. Third, agents that cause edema (histamine and thrombin) likewise stimulate the abrupt increase in shear rate followed by flow-mediated dilation. Together, this suggests a novel flow recruitment mechanism for growth factors, but also for agents that alter permeability.

To relate these vasoactive changes to other physiological effects of growth factors, it is important to note the concentration of growth factors 'at the wall' as our stimulus. Based on micropipette placement, and calculated diffusion of test agents to the wall, this concentration will be $25-50 \%$ of the concentration in the micropipette (see Methods). We report for hamster cheek pouch arterioles $\mathrm{EC}_{50}$ values on the order of $10 \mathrm{ng} / \mathrm{ml}$ or 200 pM VEGF-A and 500 pM FGF2, which is consistent with the values found by others for this tissue. Dilation with VEGF (tissue bath topically applied) in the hamster cheek pouch 
shows an apparent $\mathrm{EC}_{50}$ of approximately 1,000 pM [35]. Dilation with FGF2 (micropipette applied) in the hamster cheek pouch yields an $\mathrm{EC}_{50}$ value of approximately 100 $\mathrm{pM}$ [5]. Slightly lower $\mathrm{EC}_{50}$ values for dilation are reported in porcine coronary microvessels (approx. 10 pM) [68]. Overall, the effective dosages causing dilation range from 10 to $1,000 \mathrm{pM}[5-8,35-39]$. Permeability changes and migration/proliferation effects with VEGF-A or FGF2 occur over this same range, although frequently much higher concentrations have been tested $[4,34,35$, 40-49]. Thus, key physiological effects of growth factors (dilation, permeability, migration/proliferation) are elicited by similar concentrations in the pM range.

Basal interstitial values for VEGF (10-1600 pM) and FGF2 (10-200 pM) encompass large ranges, but overlap with the $\mathrm{EC}_{50}$ values for the key physiological effects [22, $50,51$; for reviews, see 21,23$]$. Through a variety of physiological or pathophysiological conditions, either increases dramatically: VEGF (150-95,000 pM); FGF2 (1818,000 pM) [21-23, 50, 51]. Mac Gabhann et al. [23] have modeled for VEGF the interstitial compartments where 20-40 pM VEGF is found within the matrix, and an additional $600 \mathrm{pM}$ is likely bound to specific receptors on the endothelial cells. Matrix-associated growth factors are likely encrypted within the matrix, associated with heparin and proteoglycans $[21,23,52,53]$. Mac Gabhann et al. [23] show that with exercise the matrix-associated VEGF is predicted to increase by 10 -fold, while the endothelial cell-bound pool increases by 4 -fold. This suggests that during the basal state, only $30 \%$ of the receptors are occupied as compared to the capacity with exercise. Directly relevant to the present study, this suggests a large capacity for immediate response to increased VEGF.

There is a temporal effect of growth factors on gap junctions. While chronic exposure (days) alters gap junction expression and microvascular responses [54-56], exposures of only minutes will diminish cell-to-cell communication for VEGF [57] or FGF [58]. We show that within seconds, FGF2 initiates a remote vasodilation that can be blocked by $18 \alpha \mathrm{GA}$. VEGF induces a remote dilation also requiring gap junctions, but is not blocked by $18 \alpha \mathrm{GA}$. This raises the question of whether different isoforms of connexins are involved in the separate remote responses to FGF2 and VEGF-A. Connexin isoforms found in the hamster cheek pouch tissue include $\mathrm{Cx} 37$, 40 and 43 [59]. Some studies report that $18 \alpha$ GA transiently blocks Cx 43 [60-62], but also may block other gap junctions, such as $\mathrm{Cx} 27$ [62]. This may suggest that $\mathrm{Cx} 43$ may be required for the FGF but not VEGF response.

Remote Flow Recruitment with VEGF-A and FGF2
We report a novel finding of an abrupt increase in velocity followed by a nitro-arginine-sensitive dilation in response to VEGF, histamine and thrombin. A possible reason why nitro-arginine exposure at location A could cause a decrease in remote responses emanating from the downstream location $\mathrm{C}$ would include recirculation of LNNA to that downstream site. We feel this is not likely. Care was taken to note that the pipette contents washed away from the network and was not recirculated. Further, LNNA exposure still resulted in elevated shear rate upstream. We interpret the secondary dilation to be flow mediated; using the simplest interpretation of the data, this would be flow-induced NO production. We have shown that the upstream flow-mediated dilation stimulated by downstream $\alpha_{v} \beta_{3}$ ligation for this arteriolar network location could be blocked upstream by specific inhibition of the VEGFR2 tyrosine kinase with SU1498 or VTI [10]. Thus, within this arteriolar network, we speculate that the downstream VEGF-induced secondary remote dilation is part of a more complex flow-sensing mechanism that includes NO production. Further work is required to elucidate this link.

Permeability changes are commonly reported with VEGF-A. We have questioned whether elevated permeability downstream (either in the arterioles that were exposed or the downstream capillary bed) could cause the abrupt increase in velocity upstream. To examine the theoretical feasibility, we have calculated the increase in permeability that would be required to account for the velocity increase upstream. This calculation includes a number of standard assumptions (for example, mass balance of total flow, circular cross-sectional shape, mean axial fluid velocity of the red blood cells accurately reflects the mean bulk velocity of the whole blood, no changes in oncotic pressure). Using our data for the velocity $(530 \mu \mathrm{m} / \mathrm{s})$ and diameter $(10 \mu \mathrm{m})$ measured with the VEGF remote response, the basal bulk flow is estimated as $4.2 \times 10^{-8}$ $\mathrm{ml} / \mathrm{s}$. By increasing only velocity by 1.17 -fold, per our data, peak bulk flow would be $4.9 \times 10^{-8} \mathrm{ml} / \mathrm{s}$, yielding an increase in volume flow of $0.7 \times 10^{-8} \mathrm{ml} / \mathrm{s}$; this is the volume of fluid that would need to extravasate per second due to increased permeability. One important assumption is that we presume that the excess volume flow travels to only the downstream capillary bed fed by the terminal arteriole that was stimulated. This is based on our prior work showing that the excess red blood cell flux travels only to the stimulated downstream branch in experiments with $\alpha_{v} \beta_{3}$ integrin ligation [16]. Next we estimated the downstream surface area for exchange using a published value for a typical capillary grouping (module) 
with a total length of approximately $2,800 \mu \mathrm{m}$ [28] and average capillary diameter of $5 \mu \mathrm{m}$ (hamster red blood cell is $5 \mu \mathrm{m})$; surface area per module is $4.4 \times 10^{-4} \mathrm{~cm}^{2} /$ module. The volume flow and surface area provided Jv/S from the Starling equation. For one downstream module, $\mathrm{Jv} / \mathrm{S}$ would be $8 \times 10^{-6} \mathrm{~cm} / \mathrm{s}$. It is more likely there are 3 or more modules fed by the arteriolar branch [28], and thus this value is a higher limit. This value of Jv/S is of the same order of magnitude that can be found in the literature for exposure to VEGF-A ( $50 \mathrm{ng} / \mathrm{ml}$ or $1 \mathrm{nM}$ ). Within seconds, VEGF-A increases hydraulic conductivity 2fold [4], increases small solute $(3 \mathrm{kD})$ permeability 3.3fold [40], and in the hamster cheek pouch, large solute $(150 \mathrm{kD})$ permeability is elevated as much as 10 -fold at this dose [35]. Using a basal value for Lp of $2 \times 10^{-7}$ $\mathrm{cm} \cdot \mathrm{s}^{-1} \cdot \mathrm{cm} \cdot \mathrm{H}_{2} \mathrm{O}^{-1}[4]$, and conservatively only doubling Lp with VEGF-A exposure to $4 \times 10^{-7} \mathrm{~cm} \cdot \mathrm{s}^{-1} \cdot \mathrm{cm}$. $\mathrm{H}_{2} \mathrm{O}^{-1}$, at a constant net pressure of $30-50 \mathrm{~cm} \mathrm{H}_{2} \mathrm{O}$ [4], $\mathrm{Jv} / \mathrm{S}$ would be 6 to $10 \times 10^{-6} \mathrm{~cm} / \mathrm{s}$. Thus, it is theoretically possible that an increase in downstream capillary permeability on the order of what is documented with VEGF-A could cause the magnitude of volume change required for the upstream velocity increase that we report in the present study. Clearly, more work is required to show this is the case.

Our data suggest that flow into and within arteriolar networks (fig. 1) is controlled via both 'general' and 'specific' flow recruitment mechanisms. General mechanisms elevate flow to many terminal branches of a network and are illustrated by exposure to SNP. First, there is a gap junction-mediated remote vasodilation response [17] with the subsequently recruited cell flux distributed to many branches within the network [16]. Specific mechanisms will recruit flow to a network, but all flow exclusively passes to the terminal branch that is stimulated.
This is illustrated by $\alpha_{\mathrm{v}} \beta_{3}$ integrin ligation, in which there is first an abrupt elevation in velocity of flow into the network, followed by a flow- and gap junction-mediated dilation. In this case, recruited flow exclusively travels to the branch of the network that was stimulated, to the extent that flow is stolen from other branches of the network [16]. The present study suggests that flow recruitment with FGF2 would be general, while recruitment with VEGF-A would be specific. Together, the general and specific recruitment mechanisms may alternate in physiologically important ways. For instance, growth factor release is temporally staggered during angiogenesis; we question whether the staggered vasoactive effects of the growth factors might be linked to the later sustainability of the total angiogeneic effect, as others have suggested [5]. Further, as growth factors are associated with or encrypted within the extracellular matrix, we question whether any mechanical or chemical means that uncovers or releases growth factors serves to actively modulate local flow recruitment in specific versus general ways.

In summary, we report that VEGF-A and FGF2 each initiate a response that recruits flow to the arteriolar network that was stimulated. The mechanism for FGF2 appears to be solely gap junction communication, while the mechanism for VEGF-A is partly gap junction mediated and partly due to a flow-mediated dilation. This secondary response is a novel mechanism that is likely related to the increased permeability caused by VEGF.

\section{Acknowledgments}

This work was funded by grants from the National Institutes of Health (NIH HL55492 and NIH DK68401) and the American Heart Association (AHA 0655908T).

\section{References}

1 Ferrara N, Gerber HP, LeCouter J: The biology of VEGF and its receptors. Nat Med 2003;9:669-676.

2 Rusnati M, Presta M: Fibroblast growth factors/fibroblast growth factor receptors as targets for the development of anti-angiogenesis strategies. Curr Pharm Des 2007;13: 2025-2044.

-3 Tanghetti E, Ria R, Dell'Era P, et al: Biological activity of substrate-bound basic fibroblast growth factor (FGF2): recruitment of FGF receptor-1 in endothelial cell adhesion contacts. Oncogene 2002;21:3889-3897.
-4 Glass CA, Harper SJ, Bates DO: The anti-angiogenic VEGF isoform VEGF165b transiently increases hydraulic conductivity, probably through VEGF receptor 1 in vivo. J.Physiol 2006;572:243-257.

5 Brown MD, Hudlicka O, Damon D, Duling BR: Vasoactive effects of basic and acidic fibroblast growth factors in hamster cheek pouch arterioles. Int J Microcirc Clin Exp 1996;16:308-312.

6 Laham RJ, Li J, Tofukuji M, Post M, Simons $M$, Sellke FW: Spatial heterogeneity in VEGF-induced vasodilation: VEGF dilates microvessels but not epicardial and systemic arteries and veins. Ann Vasc Surg 2003;17: 245-252.

7 Lopez JJ, Laham RJ, Carrozza JP, et al: Hemodynamic effects of intracoronary VEGF delivery: evidence of tachyphylaxis and NO dependence of response. Am J Physiol 1997; 273:H1317-H1323.

${ }_{8}$ Sellke FW, Wang SY, Stamler A, et al: Enhanced microvascular relaxations to VEGF and bFGF in chronically ischemic porcine myocardium. Am J Physiol 1996;271:H713H720. 
9 Reuss B, Dono R, Unsicker K: Functions of fibroblast growth factor (FGF)-2 and FGF-5 in astroglial differentiation and blood-brain barrier permeability: evidence from mouse mutants. J Neurosci 2003;23:6404-6412.

- 10 Jin ZG, Ueba H, Tanimoto T, Lungu AO, Frame MD, Berk BC: Ligand-independent activation of vascular endothelial growth factor receptor 2 by fluid shear stress regulates activation of endothelial nitric oxide synthase. Circ Res 2003;93:354-363.

-11 Johnson DE, Williams LT: Structural and functional diversity in the FGF receptor multigene family. Adv Cancer Res 1993;60: $1-41$.

-12 Matsumoto T, Claesson-Welsh L: VEGF receptor signal transduction. Sci STKE 2001; 2001:RE21.

-13 Brown MD, Hudlicka O: Modulation of physiological angiogenesis in skeletal muscle by mechanical forces: involvement of VEGF and metalloproteinases. Angiogenesis 2003; 6:1-14.

-14 Milkiewicz M, Brown MD, Egginton S, Hudlicka O: Association between shear stress, angiogenesis, and VEGF in skeletal muscles in vivo. Microcirculation 2001;8: 229-241.

-15 Mitsumata M, Fishel RS, Nerem RM, Alexander RW, Berk BC: Fluid shear stress stimulates platelet-derived growth factor expression in endothelial cells. Am J Physiol 1993; 265:H3-H8.

-16 Fox RJ, Frame MD: Arteriolar flow recruitment with vitronectin receptor stimulation linked to remote wall shear stress. Microvasc.Res. 2002;64:414-424.

-17 Frame MD: Increased flow precedes remote arteriolar dilations for some microapplied agonists. Am J Physiol Heart Circ Physiol 2000;278:H1186-H1195.

-18 Frame MD: Conducted signals within arteriolar networks initiated by bioactive amino acids. Am J Physiol 1999;276:H1012-H1021.

19 Frame MD, Sarelius IH: L-Arginine-induced conducted signals alter upstream arteriolar responsivity to L-arginine. Circ Res 1995;77: 695-701.

20 Brooks PC, Clark RA, Cheresh DA: Requirement of vascular integrin $\alpha_{\mathrm{v}} \beta_{3}$ for angiogenesis. Science 1994;264:569-571.

-21 Filion RJ, Popel AS: Intracoronary administration of FGF-2: a computational model of myocardial deposition and retention. Am J Physiol Heart Circ Physiol 2005;288:H263H279.

22 Kut C, Mac Gabhann F, Popel AS: Where is VEGF in the body? A meta-analysis of VEGF distribution in cancer. Br J Cancer 2007;97: 978-985.

-23 Mac Gabhann F, Ji JW, Popel AS: VEGF gradients, receptor activation, and sprout guidance in resting and exercising skeletal muscle. J Appl Physiol 2007;102:722-734.
24 Sarelius IH, Duling BR: Direct measurement of microvessel hematocrit, red cell flux, velocity, and transit time. Am J Physiol 1982; 243:H1018-H1026.

25 Fox RJ, Frame MD: Regulation of flow and wall shear stress in arteriolar networks of the hamster cheek pouch. J Appl Physiol 2002; 92:2080-2088.

26 Frame MD, Sarelius IH: Endothelial cell dilatory pathways link flow and wall shear stress in an intact arteriolar network. J Appl Physiol 1996;81:2105-2114.

27 Frame MD, Sarelius IH: Arteriolar bifurcation angles vary with position and when flow is changed. Microvasc Res 1993;46:190-205.

28 Berg BR, Sarelius IH: Functional capillary organization in striated muscle. Am J Physiol 1995;268:H1215-H1222.

29 Frame MD, Sarelius IH: Regulation of capillary perfusion by small arterioles is spatially organized. Circ Res 1993;73:155-163.

30 Rivers RJ, Frame MD: Network vascular communication initiated by increases in tissue adenosine. J Vasc Res 1999;36:193-200.

31 Cokelet GR: Experimental determination of the average hematocrit of blood flowing in a vessel. Microvasc Res 1974;7:382-384.

32 Snedecor GW, Cochran WG: Statistical Methods. Ames, The Iowa State University Press, 1974.

33 Noel AA, Fallek SR, Hobson RW, Duran WN: Inhibition of nitric oxide synthase attenuates primed microvascular permeability in the in vivo microcirculation. J Vasc Surg 1995;22:661-669.

34 Moy AB, Blackwell K, Wu MH, Granger HJ: Growth factor- and heparin-dependent regulation of constitutive and agonist-mediated human endothelial barrier function. Am J Physiol Heart Circ Physiol 2006;291:H2126H2135.

-35 Sellke FW, Wang SY, Friedman M, et al: Basic FGF enhances endothelium-dependent relaxation of the collateral-perfused coronary microcirculation. Am J Physiol 1994; 267:H1303-H1311.

36 Tiefenbacher CP, Chilian WM: Basic fibroblast growth factor and heparin influence coronary arteriolar tone by causing endothelium-dependent dilation. Cardiovasc Res 1997;34:411-417.

-37 Wu HM, Yuan Y, McCarthy M, Granger HJ: Acidic and basic FGFs dilate arterioles of skeletal muscle through a NO-dependent mechanism. Am J Physiol 1996;271:H1087H1093.

38 LeBlanc AJ, Shipley RD, Kang LS, MullerDelp JM: Age impairs Flk-1 signaling and NO-mediated vasodilation in coronary arterioles. Am J Physiol Heart Circ Physiol 2008; 295:H2280-H2288.

39 Aramoto H, Breslin JW, Pappas PJ, Hobson RW, Duran WN: Vascular endothelial growth factor stimulates differential signaling pathways in in vivo microcirculation. Am J Physiol Heart Circ Physiol 2004; 287:H1590-H1598.
40 Celia G, Osol G: Mechanism of VEGF-induced uterine venous hyperpermeability. J Vasc Res 2005;42:47-54.

$>41$ Wu HM, Yuan Y, Zawieja DC, Tinsley J, Granger HJ: Role of phospholipase C, protein kinase $\mathrm{C}$, and calcium in VEGF-induced venular hyperpermeability. Am J Physiol 1999;276:H535-H542.

-42 Wu MH, Guo M, Yuan SY, Granger HJ: Focal adhesion kinase mediates porcine venular hyperpermeability elicited by vascular endothelial growth factor. J Physiol 2003;552: 691-699.

43 Eliceiri BP, Paul R, Schwartzberg PL, Hood JD, Leng J, Cheresh DA: Selective requirement for Src kinases during VEGF-induced angiogenesis and vascular permeability. Mol Cell 1999;4:915-924.

44 Mayhan WG: VEGF increases permeability of the blood-brain barrier via a nitric oxide synthase/cGMP-dependent pathway. Am J Physiol 1999;276:C1148-C1153.

45 Issbrucker K, Marti HH, Hippenstiel S, et al: p38 MAP kinase-a molecular switch between VEGF-induced angiogenesis and vascular hyperpermeability. FASEB J 2003;17: 262-264.

-46 Shamloo A, Ma N, Poo MM, Sohn LL, Heilshorn SC: Endothelial cell polarization and chemotaxis in a microfluidic device. Lab Chip 2008;8:1292-1299.

47 Liakos P, Bourmeyster N, Defaye G, Chambaz EM, Bottari SP: ANG II AT1 and AT2 receptors both inhibit bFGF-induced proliferation of bovine adrenocortical cells. Am J Physiol 1997;273:C1324-C1334.

48 Hollborn M, Jahn K, Limb GA, Kohen L, Wiedemann P, Bringmann A: Characterization of the basic fibroblast growth factorevoked proliferation of the human Muller cell line, MIO-M1. Graefes Arch Clin Exp Ophthalmol 2004;242:414-422.

49 Hamdollah Zadeh MA, Glass CA, Magnussen A, Hancox JC, Bates DO: VEGF-mediated elevated intracellular calcium and angiogenesis in human microvascular endothelial cells in vitro are inhibited by dominant negative TRPC6. Microcirculation. 2008;15: 605-614

50 Hellsten Y, Rufener N, Nielsen JJ, Hoier B, Krustrup P, Bangsbo J: Passive leg movement enhances interstitial VEGF protein, endothelial cell proliferation, and eNOS mRNA content in human skeletal muscle. Am J Physiol Regul Integr Comp Physiol 2008; 294:R975-R982.

51 Taha Y, Raab Y, Carlson M, et al: Steroids reduce local inflammatory mediator secretion and mucosal permeability in collagenous colitis patients. World J Gastroenterol 2006; 12:7012-7018.

52 Springer ML, Banfi A, Ye J, et al: Localization of vascular response to VEGF is not dependent on heparin binding. FASEB J 2007;21: 2074-2085 
-53 Jayson GC, Gallagher JT: Heparin oligosaccharides: inhibitors of the biological activity of bFGF on Caco-2 cells. Br J Cancer 1997;75: 9-16.

-54 Abdullah KM, Luthra G, Bilski JJ, et al: Cellto-cell communication and expression of gap junctional proteins in human diabetic and nondiabetic skin fibroblasts: effects of basic fibroblast growth factor. Endocrine 1999;10:35-41.

-55 Burt JM, Steele TD: Selective effect of PDGF on connexin 43 versus connexin 40 comprised gap junction channels. Cell Commun Adhes 2003;10:287-291.

- 56 Falabella CA, Jiang H, Frame MD, Chen W: In vivo validation of biological responses of bFGF released from microspheres formulated by blending poly-lactide-co-glycolide and poly(ethylene glycol)-grafted-chitosan in hamster cheek pouch microcirculatory models. J Biomater Sci Polym Ed 2009;20: 903-922.
57 Suarez S, Ballmer-Hofer K: VEGF transiently disrupts gap junctional communication in endothelial cells. J Cell Sci 2001;114:12291235 .

58 De Vuyst E, Decrock E, De Bock M, et al: Connexin hemichannels and gap junction channels are differentially influenced by lipopolysaccharide and basic fibroblast growth factor. Mol Biol Cell 2007;18:34-46.

59 Hakim CH, Jackson WF, Segal SS: Connexin isoform expression in smooth muscle cells and endothelial cells of hamster cheek pouch arterioles and retractor feed arteries. Microcirculation 2008;15:503-514.

60 Guo Y, Martinez-Williams C, Gilbert KA, Rannels DE: Inhibition of gap junction communication in alveolar epithelial cells by $18 \alpha$-glycyrrhetinic acid. Am J Physiol 1999; 276:L1018-L1026.

61 Ishihara Y, Kamioka H, Honjo T, Ueda H, Takano-Yamamoto T, Yamashiro T: Hormonal, $\mathrm{pH}$, and calcium regulation of connexin 43-mediated dye transfer in osteocytes in chick calvaria. J Bone Miner Res 2008;23: 350-360.
62 El Sabban ME, Sfeir AJ, Daher MH, Kalaany NY, Bassam RA, Talhouk RS: ECM-induced gap junctional communication enhances mammary epithelial cell differentiation. J Cell Sci 2003;116:3531-3541.

63 Frame MD: In vivo transfection in microcirculatory research. Tooke J, Shore A, Whatmore J: The Microcirculation and Vascular Biology. Bologna, Monduzzi Editore, 2002.

64 Frame MD, Miano JM, Yang J, Rivers RJ: Localized adenovirus-mediated gene transfer into vascular smooth muscle in the hamster cheek pouch. Microcirculation 2001;8:403413.

65 Frame MD: Remote activation of arteriolar network preconditioning involves Katp channel activation and NO, ROS. FASEB J 2003;17:A139. 